\title{
NOTE ON TRANSLITERATION, TRANSCRIPTION, AND PRONUNGIATION
}

Throughout this book, the roman alphabet is used for Nepali words that appear in the text. Nepali words that are frequently used are italicized on first instance in the book except for names of people, places, deities, castes, and ethnic groups.

Nepali vowels are represented and pronounced roughly in the following way:

$\begin{array}{ll}a a & \text { as in hot } \\ a & \text { as in cup } \\ e & \text { as in lake } \\ i & \text { as in need } \\ o & \text { as in rope } \\ u & \text { as in mood } \\ a i & \text { as in guy } \\ o u & \text { as in sew }\end{array}$

Consonants are pronounced approximately the same as their English counterparts, with a few exceptions. The most common ones that are found in this text are:

$\begin{array}{ll}\text { th, } d h & \text { aspirated dental } \\ T h, D h & \text { aspirated retroflex } \\ t, d & \text { unaspirated dental } \\ T, D & \text { unaspirated retroflex } \\ c h h & \text { aspirated } c h \\ b h & \text { aspirated } b \\ g h & \text { aspirated } g\end{array}$

In addition, $s$ is used for all three of the silibants, as they are not easily distinguished by many of the Nepali speakers with whom I was working. 
Knowing which $s$ to write in Devanagri script was like a spelling test, according to one Nepali collaborator, rather than recognition of a phoneme. I have not distinguished between the vowel $i$ and the long version of it or $u$ and the long version of it for the same reason. One justification for taking such liberties is that Nepali is not the mother tongue for many Nepalis but rather a second language, and there are numerous variations on how Nepali is heard and spoken as a result. And last, the extensive conversion of Nepali into Roman script by young Nepalis on the internet and in texting has created fascinating local systems of transcription, and it seems to have affected many young people's ability to spell in Devanagri, despite the fact that Nepali is mostly phonetic.

When using the plural form of a few key Nepali words in the text, I have elected to use the English method of creating a plural noun by adding an $s$ at the end. This is due to the fact that for non-Nepali speaking readers, adding the longer plural ending in Nepali (haru) might make these key words difficult to recognize easily. In my view, it is more important for readers to learn a few key Nepali words than to conform to the Nepali plural form. In these instances, the Nepali noun appears in italics and the $s$ on the end does not. Specialists or Nepali speakers can easily recognize such instances and know that haru is implied.

Brackets are used for implied meaning. Parentheses are used for explanation. A pause or interruption in speech is indicated by three dots in a row, while omitted utterances are indicated by three dots with spaces between them. 


\section{Planning Families in Nepal}


